\title{
TIPOLOGIAS DE ASSENTAMENTOS PRECÁRIOS DO MUNICÍPIO DE ITAPETININGA
}

\author{
Alexandre José Pierini ${ }^{1}$ \\ Aline de Lima Correa ${ }^{2}$
}

\section{RESUMO}

O presente artigo discute o Plano Local de Habitação de Interesse Social que é uma estrutura utilizada e eficaz para planejar e estudar as necessidades habitacionais em cada município sendo processo participativo e com o objetivo principal de nivelamento de informações, bem como a construção de uma leitura comum de problemas prioritários, estratégia fundamental para viabilizar o processo de tomada de decisões. Esta pesquisa tem como objetivo geral apresentar as identificações referentes aos tipos de assentamentos precários no município de Itapetininga, visando o Diagnóstico Social elaborado através do Plano Local de Habitação de Interesse Social. Dessa forma neste trabalho realizou-se pesquisa sobre o Plano Local de Habitação de Interesse Social do Município de Itapetininga. Como metodologia foi utilizado o Plano Local de Habitação de interesse social organizado pela equipe da DEMACAMP. Por meio da análise do documento foi possível identificar as propostas e os meios de intervenções que o município de Itapetininga possui para atender a demanda de famílias que ocupam áreas irregulares, tendo como opção a urbanização (simples), a urbanização (complexa), reassentamento (ou realocação) e remanejamento (ou relocação), dependendo da área em que estão localizadas.

Palavras-chave: Assentamento Precário. Plano Local de Habitação. Tipo de Classificação.

${ }^{1}$ Programa de Pós-Graduação em Desenvolvimento Territorial e Meio ambiente, Centro Universitário de Araraquara - UNIARA

${ }^{2}$ Centro Universitário de Araraquara - UNIARA. 


\section{PRECARIOUS RURAL SETTLEMENTS TIPOLOGIES IN ITAPETINGA}

\section{ABSTRACT}

This paper discusses the Social Local Housing Plan which is a used and effective framework to plan and study the housing needs in each municipality, a participatory process, with the main objective of leveling information, as well as the construction of a common reading of priority issues, a key strategy to facilitate the process of decision taking. This research has as its main objective to present the IDs of the types of precarious rural settlements in the city of Itapetininga, aiming at the Social Diagnosis developed by the Local Social Housing Plan. So in this work was carried out a research on the Social Local Housing Plan in the municipality of Itapetininga. The methodology was used to reading and analysis of the Local Housing Plan of social interest organized by the DEMACAMP team The analysis of the document allowed to identify proposals and means of interventions that the municipality of Itapetininga has to meet the demand of families occupying irregular areas, having as options simple urbanization, complex urbanization, resettlement (or reallocation) and ressettlement (or relocation), depending on the area in which they are located.

Keywords: Precarious Settlements Local Housing Plan. Type of Classification.

\section{INTRODUÇÃO}

Visto a necessidade de se instituir mecanismos em auxiliar os municípios quanto à questão habitacional, surge à implementação da Política Nacional através do Ministério das Cidades que foi o órgão incumbido de organizar política para valorização do planejamento habitacional.

Diante da Política Nacional, os municípios apresentam-se com ações a serem cumpridas, dentre elas a elaboração do Diagnóstico Social através do Plano Local de Habitação de Interesse Social, que tem como objetivo identificar a questão habitacional nos municípios brasileiros.

A classificação de assentamentos precários e o tipo de intervenção para a identificação de assentamentos tem como embasamento as diretrizes apontadas pela Secretaria Nacional de Habitação do Ministério das Cidades, empregada no Plano Nacional de Habitação, sendo elas: urbanização simples, urbanização complexa, remanejamento ou relocação e reassentamento ou realocação.

Ao observar quanto às tipologias de assentamentos precários, os mesmos podem ser classificados como consolidados, consolidáveis, e não consolidados, entretanto essa classificação pode ser insuficiente para definir as tipologias de intervenção, desta forma poderá ter especificidades municipais conforme necessidade frente a realidade.

A classificação dos assentamentos deve ser realizada de forma a agrupá-los por características similares ou por tipos de problema tendo em vista o tipo de intervenção necessária. A identificação das intervenções permite prever ações e estimar os custos envolvidos.

Os municípios que definiram tipologias de agrupamento de assentamentos consideram diversas variáveis para sua classificação: localização no território, possibilidade de consolidação do assentamento, percentual estimado de reassentamento; características e restrições ambientais, densidade e tecido urbano, tipo de procedimento para regularização; porte do assentamento em 
complexos e outras.

Desta forma, ao analisar as classificações de assentamentos precários no município de Itapetininga quanto à origem, observou-se identificações com duas configurações: favelas que são as ocupações por não proprietários sem planos de ocupação pré-fixado, e loteamentos irregulares que se caracterizam por projetos implantados por agente promotor e/ ou incorporador em desacordo com a legislação, com ou sem aprovação prévia.

Este trabalho aborda especificar quanto aos termos das classificações e como apresenta a realidade do Bairro Vila Palmeira do município de Itapetininga, o tipo de assentamento, a classificação, localização, situação fundiária, restrições legais, condicionantes ambientais, características topográficas marcantes e outros pontos que forem necessários de serem mencionados.

\section{Assentamento Precário}

A partir do ano de 2003, a questão habitacional e o planejamento estatal foram reorganizados com a criação do Ministério das Cidades que foi capaz de reagrupar as áreas de habitação, saneamento, transportes públicos e ordenamento territorial. Nesse contexto, o Ministério das Cidades também vem se empenhando na elaboração de normas, leis e diretrizes. Destaca-se a estruturação da Política Nacional de Habitação (PNH) e do Sistema Nacional de Habitação (SNH) e a retomada do investimento no setor.

O SNH (Sistema Nacional de Habitação) foi instituído em 2005 e veio a estabelecer como condição para os Estados e Municípios aderirem ao SNHIS, a necessidade de elaboração do Plano Estadual de Habitação de Interesse Social (PEHIS) ou Plano Local de Habitação de Interesse Social (PLHIS), assim como a constituição de Fundo e Conselho de Habitação com representação dos segmentos da sociedade ligados à área de habitação e de um plano de habitação (estadual ou municipal).

A partir do PLHIS buscou-se organizar os assentamentos precários diante das configurações apresentadas no município.

Para Cardoso, Araujo e Ghilardi (2010)

...a denominação 'assentamentos precários' foi adotada para fazer referência, principalmente, às situações das áreas ocupadas irregularmente e que apresentam deficiências de infraestrutura e de acessibilidade classificando as "como aglomerações com delimitação mais ou menos precisa no tecido urbano, em geral, distintas do entorno quanto às suas características físicas e sociais; e com ocupação inequívoca e majoritária por população de baixa renda.

Na visão de Cardoso (2010) os assentamentos precários apresentam várias configurações: irregularidade, precariedade, vulnerabilidade e carência social. De uma forma geral, as prefeituras concentram as suas ações sobre as questões das irregularidades e das precariedades, e mesmo assim, ainda existem problemas para estabelecer procedimentos objetivos para avaliar, em cada caso de assentamento, a abrangência da sua irregularidade (se fundiária, urbanística ou de padrão e procedimentos de construção), pois em cada território a realidade é diferenciada.

A Política Nacional de Habitação (PNH) "adotou a denominação 'assentamentos precários' para indicar uma categoria de abrangência nacional e representativa do conjunto de assentamentos urbanos inadequados ocupados por moradores de baixa renda" (BRASIL, 2005; p.37). Desta forma, a categoria aborda diversas tipologias de assentamentos, tais como, cortiços, favelas, loteamentos irregulares de moradores de baixa renda e conjuntos habitacionais produzidos pelo 
setor público, em situação de irregularidade ou de degradação.

Os assentamentos precários são, portanto, porções do território urbano com dimensões e tipologias variadas, que têm em comum:

- o fato de serem áreas predominantemente residenciais, habitadas por famílias de baixa renda;

- a precariedade das condições de moradia, caracterizada por inúmeras carências e inadequações, tais como: irregularidade fundiária; ausência de infraestrutura de saneamento ambiental; localização em áreas mal servidas por sistema de transporte e equipamentos sociais; terrenos alagadiços e sujeitos a riscos geotécnicos; adensamento excessivo, insalubridade e deficiências construtivas da unidade habitacional;

- a origem histórica, relacionada às diversas estratégicas utilizadas pela população de baixa renda para viabilizar, de modo autônomo, solução para as necessidades habitacionais, diante da insuficiência e inadequação das iniciativas estatais dirigidas à questão, bem como da incompatibilidade entre o nível de renda da maioria dos trabalhadores e o preço das unidades residenciais produzidas pelo mercado imobiliário formal. (BRASIL, 2010; p. 9).

A mensuração do déficit relacionado aos assentamentos precários no país envolve não apenas a obtenção de dados, como também a construção institucional de sistemas permanentes de coleta atualizada de informações, que serve para identificar os tipos de assentamento e também para procurar métodos tendo em vista estabelecer intervenções.

O município conhece melhor a realidade local e regional através dos dados obtidos por meio do PLHIS, que busca a aproximação da realidade com o território para definir a caracterização dos tipos de assentamentos.

A questão das tipologias de assentamentos precários e intervenções dialoga tanto com conceitos já consolidados, quanto com os conceitos que ainda estão em construção e são muitas as especificidades locais e regionais a serem consideradas quando se discute conceitos e metodologias de caracterização dos assentamentos, porém a intervenção varia entre os municípios.

Visto as necessidades habitacionais e precariedade da moradia em 1995, a Fundação João Pinheiro elaborou um estudo em que se propôs a definir as necessidades habitacionais e observou-se que a grande preocupação era construir novas unidades habitacionais para atender a demanda que diante da realidade era ampla e carecia de atendimento nesta questão e vinha sofrendo com a precariedade buscando refúgio em lugares desapropriados para habitar com sua família. (SANTA ROSA; DENALDI, 2009, p.83).

Enquadrando o conceito de "precariedade" dentro da formulação das necessidades habitacionais proposta pela Fundação João Pinheiro, pode-se mencionar que se trata de uma situação identificada, trata se da ausência das moradias adequadas, deixando de existir as questões básicas para habitabilidade por ausência de infraestrutura.

Foi identificado que em inúmeras vezes a inexistência de moradia não foi o único fator, mas sim a falta de adequação para a mesma, sendo de existência precária, fazendo com que isso provocasse o déficit habitacional, tendo que construir unidades habitacionais para atender essa demanda. (SANTA ROSA; DENALDI, 2009, p.83).

Outra diferenciação em relação às metodologias apresentadas diz respeito ao objeto que está sendo definido. No caso das necessidades habitacionais, está-se falando de domicílios em situação de déficit ou inadequação. No caso da precariedade, está-se falando de assentamentos. 
Isso porque as políticas, programas ou projetos de intervenção, no segundo caso, são feitos sobre os assentamentos e não sobre unidades habitacionais tomadas isoladamente, ou seja, nestes casos, considera-se que a situação de inadequação apresenta-se concentrada em trechos claramente definidos do território.

Portanto, de acordo com Santa Rosa; Denaldi, (2009, p. 93).

Entender os assentamentos precários como aglomerações com delimitação mais ou menos precisa no tecido urbano, em geral, distintas do entorno quanto às suas características físicas e sociais; e com ocupação inequívoca e majoritária por população de baixa renda.

Essa definição pode ainda ser um pouco imprecisa no caso de assentamentos precários em áreas periféricas, mais homogêneas na sua estrutura social, mas é geral o suficiente para permitir ajustes em nível local.

Segundo Santa Rosa e Denaldi ( 2009, p. 94).

A precariedade habitacional reflete a limitação do mercado de moradias em relação à oferta de habitações que possa atender ao conjunto das necessidades da população de baixa renda, com qualidade e localização adequadas sob os aspectos ambiental e social.

Também é importante considerar o vazio deixado por muitas décadas sem políticas públicas que visassem ampliar efetivamente o acesso à terra urbanizada e a moradia.

De acordo com a história, as habitações precárias, correspondendo a soluções habitacionais informais, tiveram um tratamento diferenciado pelo poder público, segundo as conjunturas políticoeconômicas e o tipo de ocupação, o poder público procurou alternar entre medidas de remoção e de melhorias caracterizando pela insuficiência de políticas para atendimento das necessidades da população em favor ao desenvolvimento das favelas, cortiços ou dos loteamentos irregulares, tendo essas tipologias se constituído na principal solução para a questão da moradia popular no Brasil.

A partir da Constituição Federal de 1988, o conceito de assentamentos precários começou a ser construído e influenciado por meio das lutas dos movimentos sociais que buscavam garantir seus direitos visando a questão por moradia e reforma urbana, a implementação nos três níveis de governo de programas de urbanização de favelas e regularização de loteamentos irregulares, bem como através do surgimento de uma nova metodologia para o dimensionamento do déficit habitacional do país.

Após a aprovação do Estatuto da Cidade e a edição da Medida Provisória n ${ }^{\text {. }}$ 2220, em 2001, ocorreram avanços na ordem legal para a implementação de uma política nacional de urbanização e regularização fundiária dos assentamentos precários da população de baixa renda, incluindo-se no conceito de moradia digna a necessidade de regularização fundiárias dos assentamentos.

Após a criação do Ministério das Cidades em 2003, a urbanização e integração urbana dos assentamentos precários foram definidas como um dos elementos e eixo prioritário da Política Nacional de Habitação aprovado no ano de 2004. O conceito de assentamentos precários foi então ampliado, passando a englobar diferentes tipologias habitacionais, tendo como características comuns a precariedade das condições de moradia e a sua origem histórica. Definidos como uma categoria abrangente das inúmeras situações de inadequações habitacionais e de irregularidade seja urbanística quanto ao parcelamento de uso e ocupação do solo, seja ambiental com a ocupação de áreas de risco e de proteção ambiental, seja fundiária quanto à propriedade da terra. (SANTA ROSA; DENALDI, 2009, p.94).. 
O termo slum é utilizado na literatura internacional para caracterizar os assentamentos precários. De acordo com UN-Habitat (2007), slum descreve uma ampla gama de assentamentos de baixa renda e de condições precárias de vida. Conforme UN-Habitat (2003a), o termo slum era usado para caracterizar áreas deterioradas da cidade de Londres, no início do século XIX, cujos domicílios apresentavam condições precárias de construção, elevado nível de insalubridade e alta densidade populacional. Nesse sentido original, slum corresponde, no Brasil, ao termo cortiço. No entanto, o significado do termo slum se ampliou no último século. Para UN-Habitat (2007), slum denomina vários tipos de assentamentos precários que, em pouco tempo, se transformaram na mais visível manifestação da pobreza urbana dos países em desenvolvimento. (QUEIROZ, 2015).

Historicamente, o Brasil referente ao direito a habitação institucionalmente legalizado é fruto recente da última Carta Constitucional de 1988 e posterior regulamentação através do Estatuto da Cidade. No entanto, a pressão urbana sobre habitação é anterior. Percebe-se que ao longo do tempo a moradia sempre se configurou como uma dificuldade de assentamento humano, e nas últimas décadas, no Brasil, consolidaram-se organizações sociais fortemente vinculadas à luta pelo direito à moradia que buscavam a garantia dos direitos (IPEA, 2010, p.30).

Nesse contexto, é possível identificar três períodos relativos às políticas públicas sobre a questão habitacional no Brasil:

1. É notável ações apresentadas de modo descentralizadas ocorridos entre os anos de 30 e 40 , buscando alternativas para a construção de unidades habitacionais e/ou financiamento de moradia por meio de outro órgão;

2. Nos anos 60 e 70 que o Banco Nacional de Habitação promoveu a massificação da produção de moradia e a centralizou.

3. Surgiram métodos e soluções mais locais nos dias atuais de intervenção mediadas pelo poder municipal, mesmo que com financiamento de outros níveis de governo. (IPEA, 2010, p.30).

A ampliação da autonomia nas iniciativas municipais quanto à definição de agenda e no desenvolvimento de programas habitacionais é ponto positivo do processo brasileiro.

Esse processo ressalta a potencialidade da gestão municipal em ampliar a eficácia, a eficiência e a democratização das políticas. A gestão municipal teria, ainda, a virtude de ser o nível de governo que permitiria uma maior integração entre as políticas de provisão de moradias e as políticas fundiária e de controle do uso e ocupação do solo, o que ampliaria mais suas possibilidades de eficácia/eficiência (MINISTÉRIO DAS CIDADES, 2004, p.11).

Cada vez mais se busca alternativas para que a questão habitacional seja vista e tratada como forma de política pública, procurando ações que visam atender as famílias que residem em situação de precariedade e garantir a elas o direito de moradia apresentada na Carta Magna de 1988.

A idéia de habitação como direito provocou a necessidade de se repensar a cidade na tentativa de superar dificuldades da relação entre as políticas setoriais. Por outro lado, as forças ora centralizadas ora descentralizadas de ação estatal na área de habitação correspondem a continuidades de ambos os lados e à coexistência de caminhos na trajetória do Estado brasileiro. (IPEA, 2010, p.33).

Ainda nesta mesma ideia, a literatura associava problemas de moradia e pobreza à periferização, porém as periferias seriam não só lugares afastados em distância como em condições sociais, onde se expressa à desigualdade entre os moradores da cidade, desta forma podemos encontrar moradias em localizações centrais em situação de precariedade. Sendo que a precariedade de moradias está associada com a falta de serviços atrelados ocasionando em um todo problemas ao poder público que a literatura representava como um retrato de fragmentação e vitimização das pessoas no sistema capitalista.

A constituição das áreas ocupadas de forma precária, cada vez mais longe dos centros e 
intermediadas por vazios, aumentaria os custos ao poder público quanto à extensão de redes de infraestrutura, deixando à mercê a população que ocupa essas áreas, ocasionando a inexistência do direito garantida a essas famílias.

Pode-se assumir que a existência de assentamentos humanos precários é um fenômeno permanente nas cidades e que as intervenções do poder público não conseguem eliminá-los pois o município procura metodologias para contornar os problemas, todavia, assim que finaliza uma determinada área uma outra nova se constrói, isso porque ainda a demanda por moradias vem ampliando cada vez mais, sendo que o poder público trabalha para minimizar esses números buscando recursos em todas as esferas para trazer no município unidades habitacionais. (IPEA, 2010, p.35).

Por fim, percebe-se que há, em geral, grande desconhecimento quanto aos fenômenos envolvidos na existência, formação e permanência dos assentamentos precários. Existem dificuldades para empreender análises com cobertura nacional sobre o problema. Sabemos que a mensuração tanto do número de assentamentos quanto das pessoas que vivem neles é difícil de ser feita, pela dificuldade de se chegar a todos os locais, pela volatilidade dos moradores e pela dinâmica intensa de formação de novos assentamentos.

O desafio que se apresenta é compreender os mecanismos do fenômeno que pressupõem uma combinação variada de precariedade, estratégias fora da regulamentação e formas de sobrevivência acionadas pela esfera da sociabilidade e vizinhança. Deixando-nos ainda muitas questões a serem desenvolvidas a respeito da espacialidade dos assentamentos, suas distinções internas e externas, as consequências para seu entorno, entre outros assuntos. (IPEA, 2010, p.36).

A caracterização da vulnerabilidade pela falta de equipamentos sociais e precariedade de serviços de infraestrutura está diretamente ligada ao planejamento urbano e à intervenção da produção do espaço urbano, necessitando que a gestão municipal busque alternativas para conciliar métodos frente à realidade social.

A diversidade está presente em todo momento nas discussões sobre os bolsões de moradias irregulares, como as mesmas surgem e como enfrentar as problemáticas em que as perseguem quanto se tratar de intervenções do poder público com as famílias consolidados naquele determinado território.

Os problemas habitacionais urbanos e a dinâmica dos assentamentos precários nas cidades incluem requisitos que vão além dos limites político administrativos dos municípios autônomos. Desde muito tempo a necessidade por moradia percorreu na historia, cada vez mais se busca soluções para diminuir com essa problemática, entretanto, percebe-se que a demanda carente por uma uma moradia digna é significativa.

É visível a importância de articulação entre todas as esferas, visando uma política pública adequada para atender o setor habitacional no país minimizando a precariedade. (IPEA, 2010, p.51).

\section{METODOLOGIA}

\section{Análise do Plano Local de Habitação de Interesse social}

\section{Assentamento precário no município de Itapetininga/ Sp}

O Plano Local de Habitação de Interesse Social foi elaborado no município de Itapetininga pela Equipe (DEMACAMP Planejamento, Projeto e Consultoria, 2011), para realizar a contextualização da problemática habitacional no local. 


\section{Ocupações irregulares e intervenção do poder público}

Conforme a (DEMACAMP Planejamento, Projeto e Consultoria, 2011), No município de Itapetininga / SP, a expansão da periferia começou por volta de 1986 e seguiu até 2011. Nesse período, ocorreu um duplo movimento no que se refere às ocupações que cresceram de forma irregular de glebas vazias, terrenos públicos, área de proteção permanente de cursos d'água (APP), mas por outro lado, a Prefeitura Municipal de Itapetininga ampliou os meios de intervenção como forma de promotora ou parceira de empreendimentos habitacionais.

Ainda de acordo com a (DEMACAMP Planejamento, Projeto e Consultoria, 2011).

Ocorrem dois períodos distintos sob o ponto de vista da promoção pública de habitações de interesse social (HIS) de 1986 a 2002 e de 2003 a 2011. No primeiro período a maioria dos empreendimentos foi contratada com a Companhia de Desenvolvimento Habitacional e Urbano do Estado de São Paulo (CDHU) e no segundo, com o Ministério das Cidades, através da Caixa Econômica Federal (CEF) e, mais recentemente, do Fundo Nacional de Habitação de Interesse Social (FNHIS).

Verificou-se que durante 25 anos a Prefeitura diversificou ações e que alcançaram resultados positivos em algumas modalidades de soluções nas questões habitacionais. Desta forma, o poder público não conseguiu dominar ou dar um direcionamento seletivo ao desenvolvimento da periferia de Itapetininga, prosseguindo a fragmentação e a dispersão urbana.

De acordo com a (DEMACAMP Planejamento, Projeto e Consultoria, 2011), a extensão urbana desordenada continuou neste momento mais recente, consequente dos seguintes pontos:

\footnotetext{
As obras de reurbanização e regularização atuais são executadas em um tecido urbano ainda disperso constituído pelos loteamentos de periferia das etapas anteriores e localizados distantes da área central.

Os novos empreendimentos de conjuntos habitacionais situam-se em glebas na periferia e, por vezes, isoladas induzindo novas frentes de ocupação dispersa, ainda que dentro de perímetro urbano.

Os loteamentos públicos empreendidos pela Prefeitura são com frequência reurbanizações de parcelamentos existentes com irregularidades anteriores e com localizações periféricas.

As favelas e ocupações que surgem nesses 25 anos estão espalhadas e carecem de projetos de urbanização; há muitos casos de famílias removidas para assentamentos distantes do local original.

As disposições do Plano Diretor de 2007 e da Política Municipal de Habitação de 2008 quantos aos fins habitacionais do Zoneamento Urbano ainda não foram compatibilizados e mapeados de modo seletivo quanto às direções da expansão urbana.
}

A intervenção da Prefeitura está atrelada a diversas modalidades de ações diante a regularização habitacional com parcerias com a ação privada e em convênios com o Governo Federal e Estadual para a construção de novas unidades habitacionais, buscando possibilidades de intervir e controlar o aumento da questão urbana em todo município.

De 1950 a 1965 ocorreu a formação da primeira periferia, tendo como características comuns as mesmas de outras cidades paulistas e algumas peculiaridades da cidade de Itapetininga.

A Prefeitura do município não tinha dados efetivos, mas percebe-se que ocorreu um significativo aumento no setor imobiliário, com inúmeros loteamentos a venda, mas não dispondo de infraestrutura adequada para o local e nenhum tipo de serviço público, sendo que os empreendedores dessas áreas acabaram deixando de cumprir seus deveres.

O foco do município estava voltado a atender famílias de baixa renda que eram empregadas no local e necessitavam de moradia e buscava meios para atrair empresas na região sendo a tônica do discurso vigente. 
A demanda de famílias de baixa renda era grande e necessitava de novos loteamentos para suprir a necessidade, desta forma devido a urgência em atender as famílias. Nesse contexto, o município começou abrir mão das exigências legais para a aprovação de loteamentos. (DEMACAMP Planejamento, Projeto e Consultoria, 2011, p. 50).

O desequilíbrio entre as dinâmicas de desenvolvimento e de expansão territorial nesse período da evolução urbana atinge números dramáticos. Por um lado, loteamentos ou partes grandes de loteamentos antigos que permanecem ociosas ou sub - ocupadas e edificados até hoje, por outro lado, loteamentos que ultrapassam $60 \%$ de lotes ocupados e edificados clandestinamente em poucos a nos e cujo histórico de irregularidades é bastante elevado. $\mathrm{O}$ descompasso entre crescimento populacional e oferta de empregos regulares também aumenta, no período em exame, as situações informais de trabalho e o subemprego que são formas de ocupação exercidas predominantemente nas áreas centrais e de urbanização consolidada de Itapetininga. Equipe (DEMACAMP Planejamento, Projeto e Consultoria, 2011, p. 52).

\title{
Unidades Habitacionais
}

Conforme estudo da (DEMACAMP Planejamento, Projeto e Consultoria, 2011), até vinte anos atrás, o município de Itapetininga proporcionou a promoção de habitação para famílias de baixa renda. Neste período, a venda a prazo de lotes tornou-se mais acessível para atender as famílias.

Os bairros ou jardins de maior tamanho se tornaram populares no processo de ocupação e não se enquadraram como empreendimentos populares, já que nesses loteamentos com lotes de grandes dimensões o valor de acesso era mais barato, onde mais de uma família adquiria o lote para obter agilidade no processo de edificação, uma vez que as prestações dos lotes ou demais custos eram divididos entres essas famílias.

De acordo com a (DEMACAMP Planejamento, Projeto e Consultoria, 2011), não há registros consolidados a partir do início da primeira periferia (1955) sobre os loteamentos que surgiram até o início da promoção por parte do setor público por volta da década de 90 . Sobre o que se refere os empreendimentos construídos por parte do setor público é possível observar que resultaram após a reurbanização total ou parcial de loteamentos.

\section{Precaridade Habitacional no Município}

\begin{abstract}
Através do Plano Local de Habitação de Interesse Social, o Diagnóstico Social conseguiu identificar as questões problemáticas relacionadas a habitação ocorridas a partir dos desequilíbrios da progresso urbano no município de Itapetininga ao decorrer do tempo e diante outros fatores seguidos dos instrumentos de intervenção e gestão tratando se da construção de moradias pelo setor público voltada para atender famílias de baixa renda.

Ainda de acordo com a Equipe, a expansão territorial sem ordenamento da periferia urbana criou um tecido urbano disperso e fragmentado. A localização de indústrias fora da cidade e de macro - equipamentos cujos acessos se dão por rodovias e estradas vicinais, induziu simultaneamente essa dispersão. Resultam desse padrão de ocupação diversos loteamentos isolados irregulares entremeados de vazios urbanos especulativos. A baixa densidade populacional bruta dessa ocupação periférica encarece os custos dos sistemas de infraestrutura que dão pretexto para a não execução a contento das redes e serviços locais de cada bairro pelo respectivo loteador. (DEMACAMP Planejamento, Projeto e Consultoria, 2011, p. 141).
\end{abstract}

Através do diagnóstico elaborado percebeu-se que as ações empreendedoras da Prefeitura iniciaram por volta do ano de 1990 e são de forma corretivas e parciais em loteamentos adjacentes à marca da área urbana central, tendo com facilidades através da infraestrutura disponibilizada. Observou-se que os 
empreendimentos construídos por meio da Companhia de Desenvolvimento Habitacional e Urbano do Estado de São Paulo estão localizados de forma distantes das áreas centrais.

Neste mesmo período foi notável o surgimento de favelas e ocupações de forma irregular em áreas de faixas ou desocupadas de proprietários particulares cujos moradores passam a demandar ações corretivas e parciais do poder público. (DEMACAMP Planejamento, Projeto e Consultoria, 2011, p. 141).

A falta de políticas urbanas e de ações preventivas para disciplinas os novos empreendimentos e as dimensões amplas do tecido urbano da periferia criam uma relação causa-efeito onde a cada tentativa de regularização pontual correspondem novas ocupações, ainda que de pequeno porte. Nem mesmo a ação mais incisiva do poder público no período seguinte (1995-2002) consegue reduzir significativamente a disseminação da precariedade habitacional a várias partes da área urbanizada de Itapetininga. (DEMACAMP Planejamento, Projeto e Consultoria, 2011, p. 141).

\section{Assentamentos Precários no Município de Itapetininga}

A figura 1 caracteriza os assentamentos precários de Itapetininga totalizando vinte áreas que deverão ser objeto de intervenção do Plano Local de Habitação de Interesse Social.

Figura 1 - Assentamentos Precários de Itapetininga - SP.

\begin{tabular}{|c|c|c|c|c|}
\hline & \multirow[t]{2}{*}{ Nome } & \multicolumn{2}{|c|}{ Configuraçăo } & \multirow[t]{2}{*}{ Origem } \\
\hline & & $\begin{array}{l}\text { Diagnóstico } \\
\text { Habitacional }\end{array}$ & $\begin{array}{l}\text { Adotada pelo } \\
\text { PLHIS }\end{array}$ & \\
\hline I. & Jd. Bela Vista & favela & favela & $\begin{array}{l}\text { Ocupaçăo de área de lazer e } \\
\text { de APP }\end{array}$ \\
\hline 2. & V. Belo Horizonte & cortiço & favela & ocupação de área do DER \\
\hline 3. & V. Belo Horizonte & - & favela & $\begin{array}{l}\text { Ocupação de APP e faixa de } \\
\text { estrada de domínio do DER }\end{array}$ \\
\hline 4. & Vila Nastri I A & favela & favela & Ocupação de área de lazer \\
\hline 5. & Vila Nastri I B & favela & favela & $\begin{array}{l}\text { Ocupaçāo faixa de linha de } \\
\text { transmissāo de energia }\end{array}$ \\
\hline 6. & Vila Nastri I C & favela & favela & $\begin{array}{l}\text { Ocupação de área de lazer e de } \\
\text { APP }\end{array}$ \\
\hline 7. & Vila Nastri II AVB & favela. & favela & Ocupação de APP \\
\hline 8. & Vila Francisca I & favela & favela & Ocupação de APP \\
\hline 9. & Vila Franciscall & favela & ocupaçắo & $\begin{array}{l}\text { Ocupação de parte de quadra } \\
\text { de loteamento }\end{array}$ \\
\hline 10. & Central Pq 4L & favela & favela & $\begin{array}{l}\text { Ocupação de área de lazer e de } \\
\text { APP }\end{array}$ \\
\hline 11. & V. Paulo Ayres & $\begin{array}{l}\text { loteamento } \\
\text { irregular }\end{array}$ & favela & $\begin{array}{l}\text { Ocupação de área de lazer e de } \\
\text { faixa de estrada de domínio do } \\
\text { DER }\end{array}$ \\
\hline 12. & V. Carolina & & fovela & Ocupaçāo de APP \\
\hline 13. & Vila Sotemo & favela & ocupaçāo & $\begin{array}{l}\text { Ocupação de área para } \\
\text { alargamento de estrada }\end{array}$ \\
\hline 14. & Vila Mazzei & $\begin{array}{c}\text { loteamento } \\
\text { irregular }\end{array}$ & ocupaçāo & $\begin{array}{l}\text { Ocupação de lotes da quadra } 3 \\
\text { do loteamento }\end{array}$ \\
\hline 15. & V. Palmeira (PitoAceso) & favela & ocupaçāo & $\begin{array}{l}\text { Ocupação de faixa para } \\
\text { alargamento de rua }\end{array}$ \\
\hline 16. & V. Piedade AVB & $\begin{array}{c}\text { loteamento } \\
\text { irregular }\end{array}$ & $\begin{array}{c}\text { re- } \\
\text { parcelamento }\end{array}$ & Ocupação de área lazer \\
\hline 17. & Jd. Maricota AVB & EHPúblico & $\begin{array}{l}\text { re- } \\
\text { parcelamento }\end{array}$ & Ocupaçāo de área lazer \\
\hline 18. & Vila Sônia & EHPúblico & EHPúblico & Ocupaçāo de apartamentos \\
\hline 19. & Vila Sudeste & EHPúblico & EHPúblico & $\begin{array}{l}\text { Loteamento privado } \\
\text { desapropriado pela PMI }\end{array}$ \\
\hline 20. & Rechā (Vicente Langoni) & $\begin{array}{l}\text { loteamento } \\
\text { irregular }\end{array}$ & $\begin{array}{l}\text { loteamento } \\
\text { irregular }\end{array}$ & Loteamento privado \\
\hline
\end{tabular}

Fonte: DEMACAMP, 2011. 
Conforme estudo pela (DEMACAMP Planejamento, Projeto e Consultoria, 2011), as áreas citadas acima na tabela totalizam oito, sendo esses objetos de estudos e análise no domínio do Programa Cidade Legal.

Foi identificado pela Equipe que na maioria dos assentamentos enquadrados como favela ocorreu à ocupação de sistemas de lazer de loteamentos existentes e de áreas de preservação permanente. Desta forma observou se que duas dessas favelas estão localizadas em áreas de faixa de estrada de domínio cujo responsável é o Departamento de Estradas de Rodagem - DER e faixa de segurança de linha de transmissão de energia, apenas em uma das áreas de favela, se estabelece a ocupação de área pública patrimonial pertencente ao Departamento de Estradas de Rodagem.

Há quatro áreas ocupadas às quais estão situadas e sucede de diretriz de alargamento de rua, dois são Pito Acesso/Vila Palmeira e Vila Sotemo. Já a Vila Francisca II é caracterizada como ocupação, que constitui parte de quadra de loteamento regular cuja planta não foi localizada.

Percebeu-se no Diagnóstico que o grupo cuja tipologia está identificada como re-parcelamento é constituído por dois assentamentos, um na na Vila Piedade e o outro no Jardim Maricota e tiveram procedência através da ocupação de sistemas de lazer de loteamentos devidamente aprovados, no qual essas áreas foram ocupadas de maneira natural e doadas para Associações de moradores com o intuito de que o local fosse regularizado.

Foi identificado pela (DEMACAMP Planejamento, Projeto e Consultoria, 2011), que no município há dois assentamentos que se enquadram na tipologia de Empreendimentos Habitacionais Públicos, entretanto constam dificuldades de regularização, pois os mesmos são áreas que passaram por desapropriações por parte da Prefeitura Municipal localizadas na Vila Sudeste, tendo como objetivo a análise para possibilidade de entrar no processo de regularização fundiária após estudo por meio do Programa Cidade Legal. No que se refere a irregularidade em conjunto habitacional localizado na Vila Sônia, trata se de empreendimento construído por meio da Companhia de Desenvolvimento Habitacional do Estado de São Paulo, estando limitada à ocupação de trinta e dois apartamentos.

No município foi constatado que há apenas um loteamento que se trata na tipologia de loteamento irregular este sendo no Distrito de Rechã, sendo área privada onde o proprietário promoveu o parcelamento de solo sem aprovação legal do loteamento, não oferecendo infraestrutura para o local.

\section{Assentamentos não consolidáveis}

De acordo com (DEMACAMP Planejamento, Projeto e Consultoria, 2011), há duzentos e oitenta e nove assentamentos não - consolidáveis. Abaixo segue a figura correspondente ao assentamento não consolidáveis (Figura 2).

Figura 2 - Assentamento Não Consolidável

\begin{tabular}{|c|c|c|}
\hline Nome & Origem & Nodedomicilios \\
\hline V. Belo Horizonte (DER) & Ocupaçāo de área do DER & 08 \\
\hline Pifo Aceso/V.Palmeira & Ocupaçāo de diretriz viária & 250 \\
\hline V. Nastri I B & $\begin{array}{l}\text { Ocupaçáo de faixa de linha } \\
\text { de transmissão }\end{array}$ & 02 \\
\hline V. Francisca I & Ocupaçāo de APP & 10 \\
\hline V. Francisca II & ocupaçâo de quadra & 11 \\
\hline V. Carolina & ocupaçāo de APP & 08 \\
\hline TOTAL & & 289 \\
\hline
\end{tabular}

Fonte: DEMACAMP, 2011. 
Segundo (DEMACAMP Planejamento, Projeto e Consultoria, 2011).

Sobre os assentamentos Vila Francisca II e Pito Acesso/ Vila Palmeira, cabe a observação de que o primeiro poderia ser considerado consolidável e o segundo parcialmente consolidável, mas a opção da Prefeitura é pela remoção total das unidades.

\section{Assentamentos Consolidáveis}

Na visão de (DEMACAMP Planejamento, Projeto e Consultoria, 2011), os assentamentos com a classificação de consolidáveis oferecem meios de intervenção de maneiras diferenciadas, por se tratar de remanejamento de moradias, o número de domicílios que deverão ser remanejados, que compreendem $17,8 \%$ do total.

A seguir a figura 3 com os respectivos assentamentos.

Figura 3 - Assentamentos Consolidáveis

\begin{tabular}{|l|c|c|c|}
\hline Nome & No de domicilios & No de remanejamentos \\
\hline Piedade A e B & 36 & & \\
\hline V. Nastri I C & 15 & 15 & \\
\hline V. Sotemo & 131 & 11 & \\
\hline TOTAL & 146 & 26 & \\
\hline Fonte: Elaboraçáo DEMACAMP, 2011. & & & \\
\hline
\end{tabular}

Fonte: DEMACAMP, 2011.

\section{Assentamentos Parcialmente Consolidáveis}

A partir do diagnóstico social elaborado, apenas os índices de remoção superiores a 10\% do total de domicílios se enquadram na classificação como parcialmente consolidáveis. Percebeu-se na tabela abaixo que o grupo envolveu assentamentos totalizando de trezentos e quarenta e quatro domicílios, tendo a necessidade de intervir através de remoção de oitenta e cinco desses, representando por volta de $25 \%$ do total.

Segue a figura 4 para que sejam observados os dados:

Figura 4 -Assentamentos parcialmente consolidáveis

\begin{tabular}{lcc|}
\hline Nome & $\mathbf{N}^{0}$ de domicílios & $\mathbf{N}^{\circ}$ de remoçóes \\
\hline Vila Nastri II A/B & 40 & 16 \\
\hline Jardim Bela Vista & 80 & 22 \\
\hline Jd. Maricota A e B & 46 & 06 \\
\hline Central Pque. Quatro L & 88 & 10 \\
\hline V. Belo Horizonte & 40 & 16 \\
\hline V. Mazzei & 50 & 15 \\
\hline TOTAL & 344 & 85 \\
\hline Fonte: Elaboraçāo DEMACAMP, 2011. &
\end{tabular}

Fonte: DEMACAMP, 2011. 
Nesse grupo é necessário observar que podem se apresentar eventuais discrepâncias quanto à denominação e delimitação dos assentamentos, pois três, Vila Mazzei, Jardim Maricota e Central Parque Quatro L, são objeto do Programa Cidade Legal, cujo foco está voltado na agilização de processos de regularização fundiária, e encontra-se em fase de checagem de informações de campo com informações contidas em plantas e documentos disponíveis. (DEMACAMP Planejamento, Projeto e Consultoria, 2011, p. 149).

\section{Assentamentos Consolidados}

Os assentamentos consolidados apresentados na figura 5 mostram que quatrocentos e setenta e três domicílios necessitam passar pelo processo de regularização fundiária.

Figura 5 - Assentamentos Consolidados

\begin{tabular}{|c|c|c|}
\hline Nome & origem & Nomedomicilios \\
\hline V. Paulo Ayres & ocupaçáo de área de uso comum & 22 \\
\hline V. Nastri I A & ocupaçáo de área de lazer & 30 \\
\hline V. Sonia & ocupaçāo de unidades & 32 \\
\hline V. Sudeste & loteamento assumido pela PMI & 229 \\
\hline Rechä & loteamento clandestino & 160 \\
\hline TOTAL & & 473 \\
\hline
\end{tabular}

Fonte: DEMACAMP, 2011.

A figura 6 representa a Quantificação das Intervenções em Itapetininga.

Figura 6 - Quantificação das Intervenções

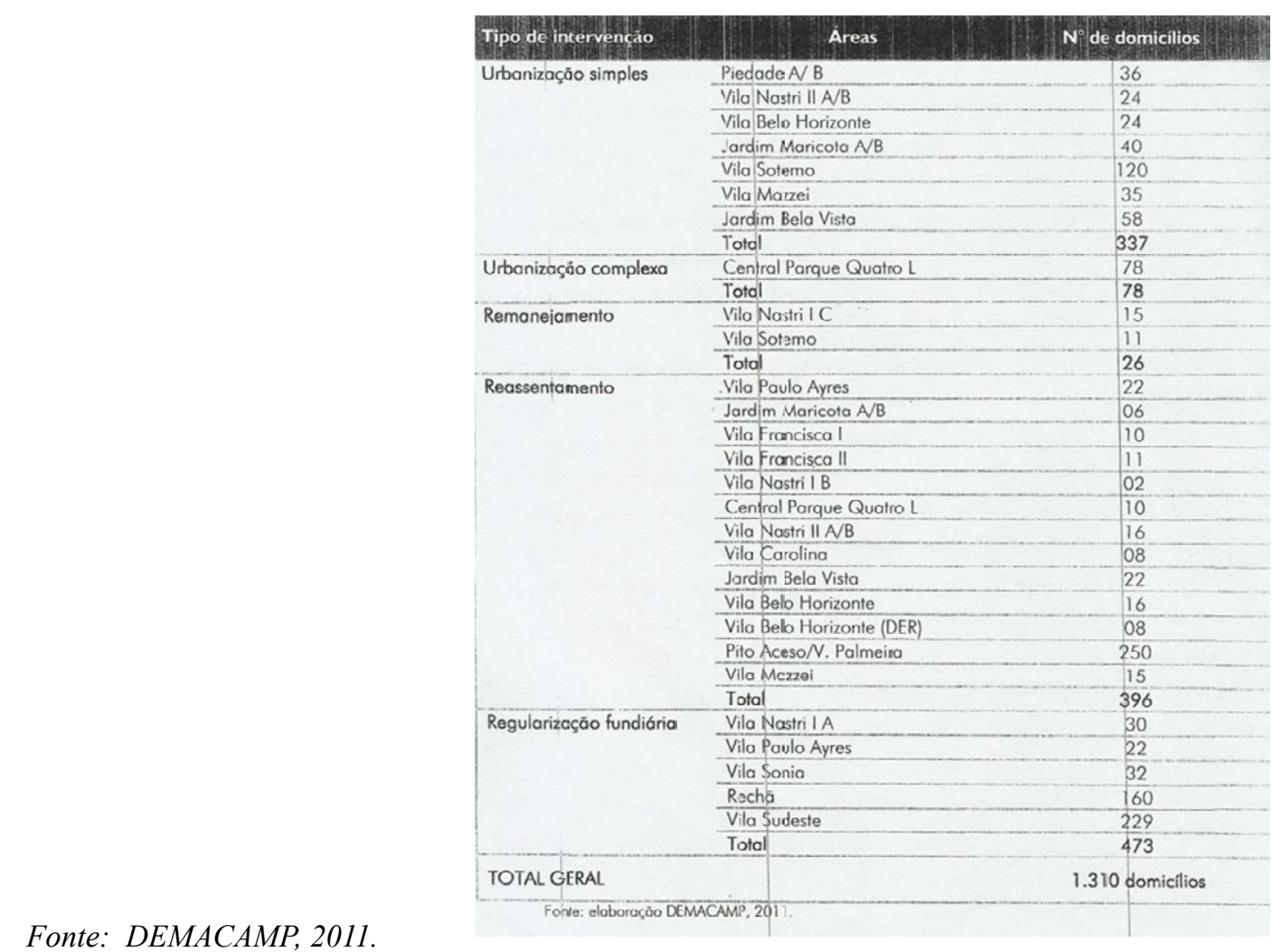


De acordo com a (DEMACAMP Planejamento, Projeto e Consultoria, 2011), após a quantificação e a classificação foram obtidos os números correspondentes aos tipos de assentamentos precários no município de Itapetininga em sua maior parte não demandam obras complexas de infraestrutura de modo que se enquadra dentro da demanda de urbanização simples. Pode-se notar que a área do Central Parque Quatro L, encontra-se classificada como urbanização complexa. Desta forma a quantidade necessária de remoções estimada é bastante significativa (396 domicílios de um total de 1.310), correspondendo a $30 \%$ do total.

As figuras 7 a 10 representam Assentamento Não Consolidável, tendo ocupação de diretriz viária de utilidade pública, com 250 domicílios, localizada em região central (limítrofe), desta forma a Prefeitura Municipal de Itapetininga optou pela remoção e reassentamento das famílias que ocupam a área no Bairro Pito Acesso/ Vila Palmeira, estando em anexo a Rua Juracy Galvão, Rua Padre João Cristiano Peter, Rua Fernando Vieira de Almeida, Rua José Jorge Musa Soares, Rua Pedro de Almeida, Avenida Padre Antonio Brunetti com prolongamento da mesma rua e Ruas Não Oficiais, totalizando $38.419 .20 \mathrm{~m}^{2}$.

Figura 7 - Assentamento Não Consolidável - Bairro Pito Acesso/ Vila Palmeira

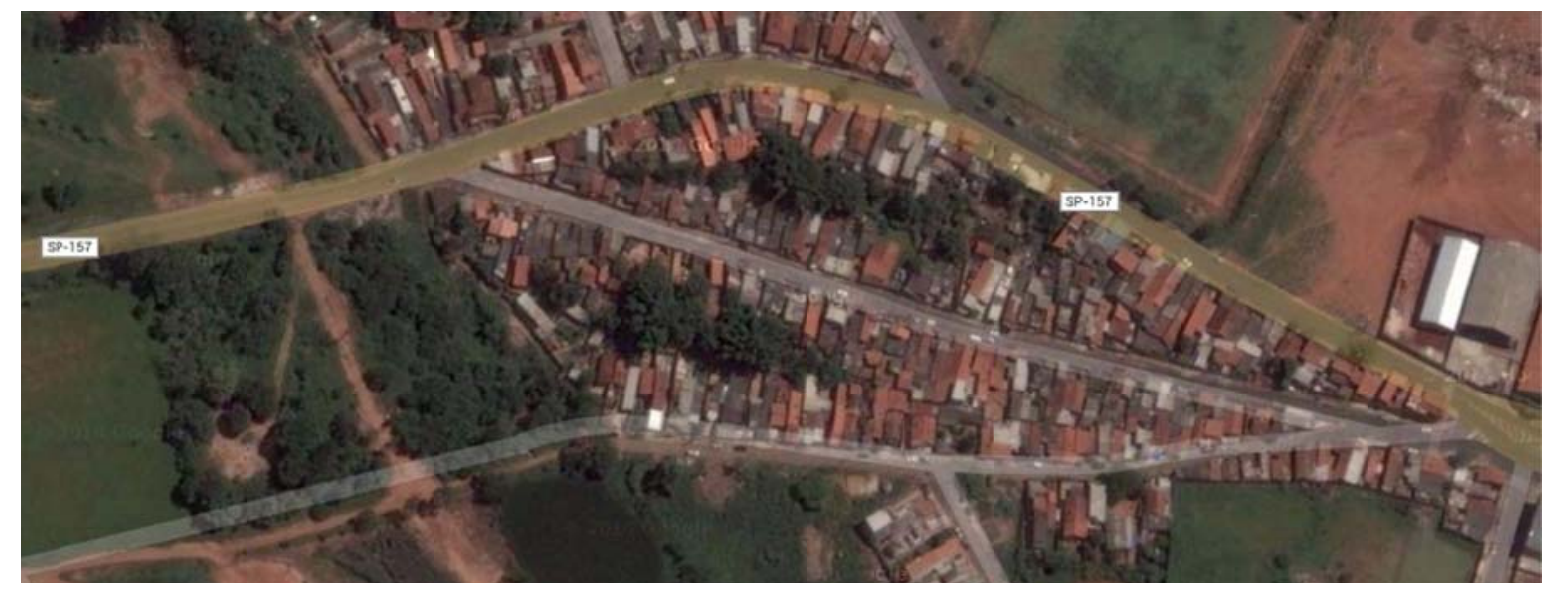

Fonte: Google Maps. Acesso em: 20 de fev. 2015

Figura 8 - Assentamento Não Consolidável - Bairro Pito Acesso/ Vila Palmeira

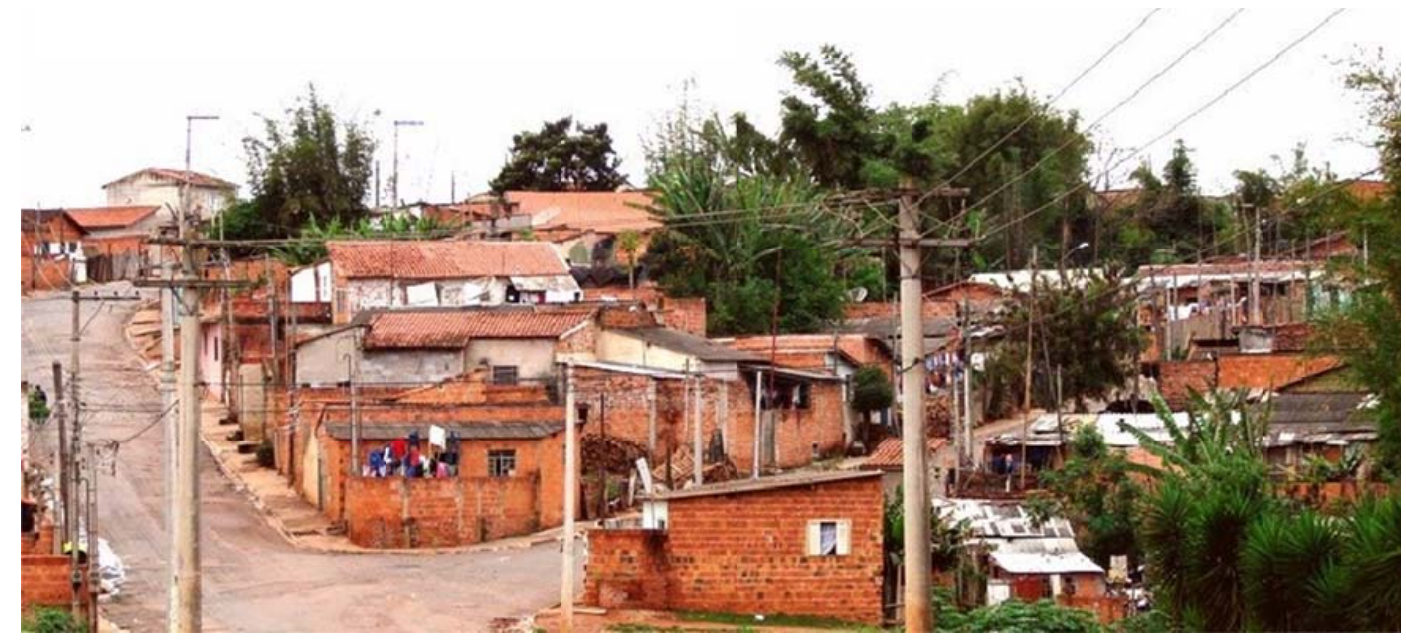

Fonte: Google Maps. Acesso em: 20 de fev. 2015 
Figura 9 - Assentamento Não Consolidável - Bairro Pito Acesso/ Vila Palmeira

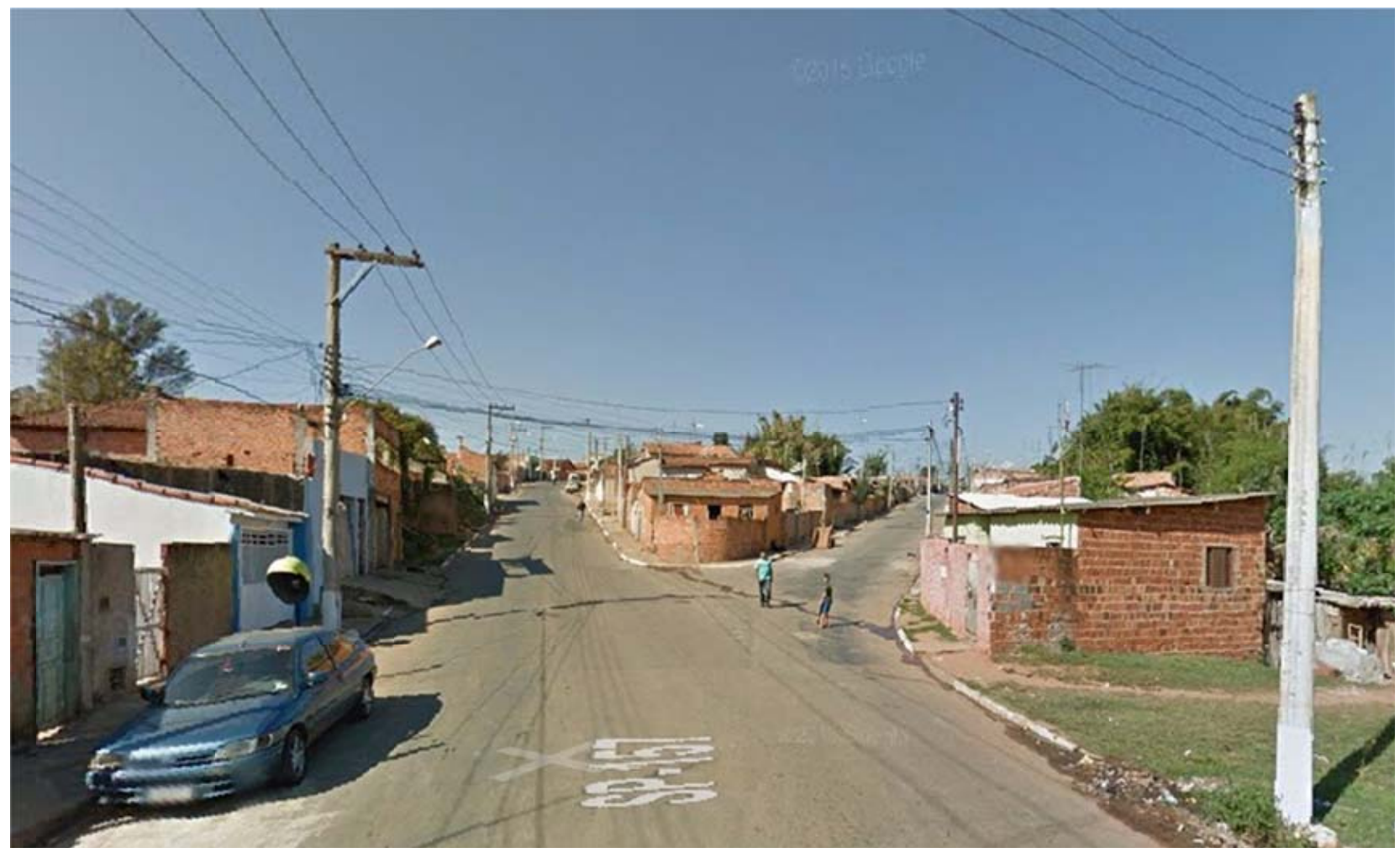

Fonte: Google Maps. Acesso em: 20 de fev. 2015

Figura 10 - Assentamento Não Consolidável - Bairro Pito Acesso/Vila Palmeira

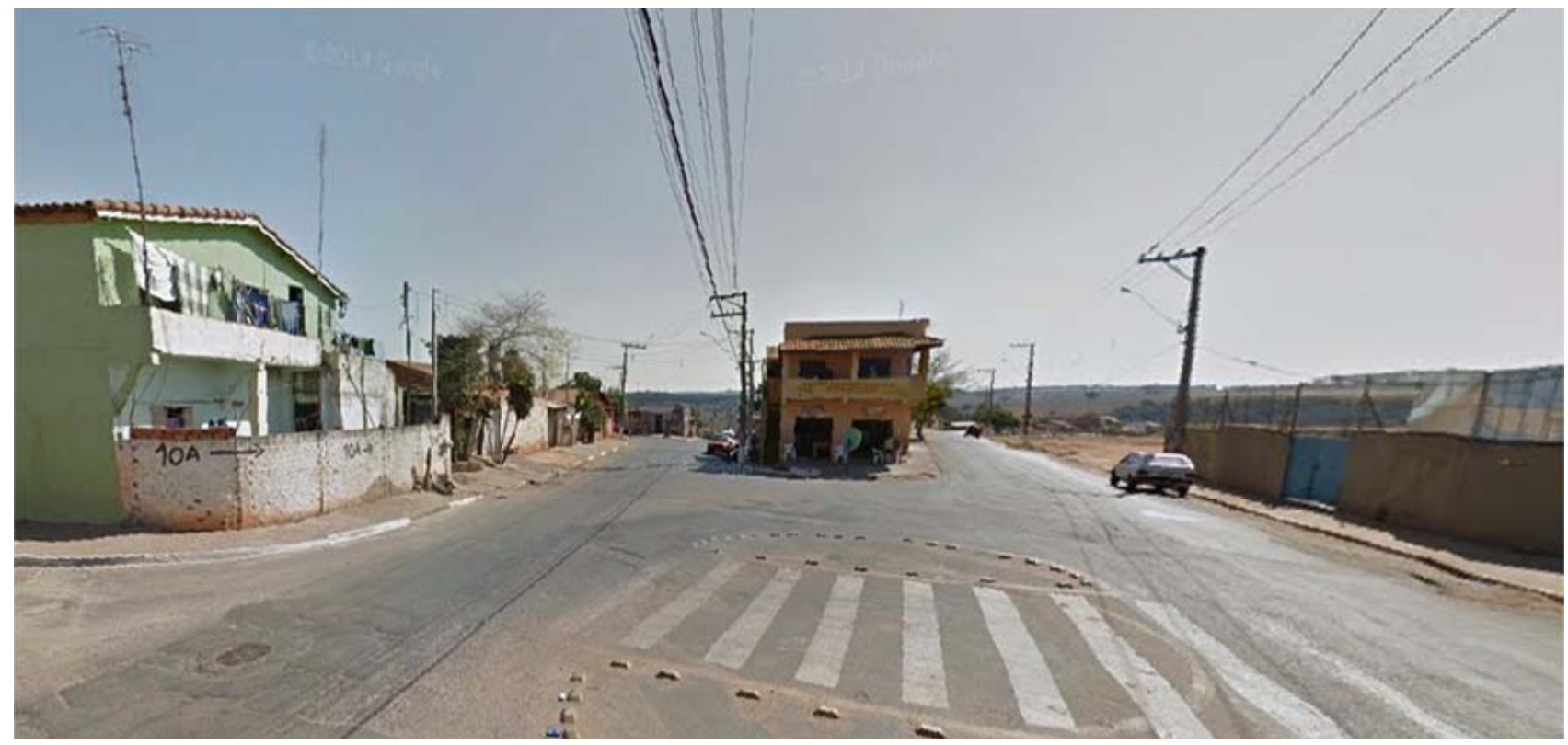

Fonte: Google Maps. Acesso em: 20 de fev. 2015 


\section{Demanda por Moradia}

De acordo com os objetivos de identificação das principais necessidades habitacionais do município, para o planejamento da demanda por terra urbanizada e custo de atendimento habitacional, consideramos que esses dados, com as devidas ressalvas, poderão ser adotados pelo Plano Local de Habitação de Interesse Social. Para Itapetininga, a projeção do Centro de Desenvolvimento e Planejamento Regional (CEDEPLAR) da Universidade Federal de Minas Gerais (UFMG) sobre o total de domicílios entre os anos 2010 e 2023 traz os seguintes valores. (DEMACAMP Planejamento, Projeto e Consultoria, 2011, p. 161).

Figura 11 - Projeção do total de domicílios, Itapetininga - SP (2010-2023)

\begin{tabular}{|cc|}
\hline Ano & Total de Domicilios \\
\hline 2010 & 47.199 \\
\hline 2011 & 48.501 \\
\hline 2012 & 49.709 \\
\hline 2013 & 50.853 \\
\hline 2014 & 51.963 \\
\hline 2015 & 53.072 \\
\hline 2016 & 54.212 \\
\hline 2017 & 55.410 \\
\hline 2018 & 56.688 \\
\hline 2019 & 58.061 \\
\hline 2020 & 59.515 \\
\hline 2021 & 61.027 \\
\hline 2022 & 62.574 \\
\hline 2023 & 64.132 \\
\hline
\end{tabular}

Fonte: DEMACAMP a partir de OLIVEIRA, GIVISIEZ e RIOS-NETO (2009).

Conforme a (DEMACAMP Planejamento, Projeto e Consultoria, 2011), o Plano Local de Interesse Social busca abordar os objetivos para apresentar a direção para novas moradias no município. Os números mostram que o PLHIS (2011-2023) a projeção por unidades habitacionais era no total de 16.933, entretanto 5.518 na faixa de 0 a 3 salários mínimos e 3.382 na faixa de 3 a 5 salários mínimos. As faixas de renda foram baseadas com o Censo 2000, dado que é a última fonte de informação censitária disponível para o nível municipal.

A figura 12 apresenta o fluxo de formação de novos domicílios entre os anos de 2011 e 2023 em Itapetininga.

Figura 12 - Projeção e novos domicílios, Itapetininga (2010-2023).

\begin{tabular}{|l|c|c|}
\hline Faixas de Renda & Distribuiçāo \% & Total \\
\hline 0 a 3 s.m. & $32,59 \%$ & 5.518 \\
\hline 3 a 5 s.m. & $19,97 \%$ & 3.382 \\
\hline Subtotal 0 a 5 s.m. & $52,56 \%$ & 8.900 \\
\hline 5 a 10 s.m. & $25,61 \%$ & 4.336 \\
\hline Mais de 10 s.m. & $21,83 \%$ & 3.697 \\
\hline TOTAL & $100 \%$ & 16.933 \\
\hline
\end{tabular}

Fonte: DEMACAMP a partir de OLIVEIRA, GIVISIEZ e RIOS-NETO (2009) e Censo Demográfico 2000 - IBGE. 


\section{CONSIDERAÇÕES FINAIS}

O presente trabalho abordou a temática referente às tipologias de assentamentos precários tratando-se de áreas irregulares, precárias, em situação de vulnerabilidade e que se encontra em carência social.

O trabalho apresentou as classificações de assentamentos, denominadas em abrangência nacional para identificar moradias com características de forma inadequada de habitabilidade, tendo como ocupantes famílias de baixa renda.

Foi mencionada a caracterização dos assentamentos como consolidados, consolidáveis e não consolidáveis, as características físicas de assentamentos no que se trata das condições do terreno, infraestrutura e os tipos de intervenções nos assentamentos.

A pesquisa realizada buscou autores que falam sobre os tipos de assentamentos e caracterização, apresentando conceitos e definições que cada autor tem sobre o assunto.

Através do Diagnóstico Social elaborado pela Equipe (DEMACAMP Planejamento, Projeto e Consultoria, 2011), foi possível conhecer o Plano Local de Habitação de Interesse Social do município de Itapetininga/SP, que busca identificar os tipos de assentamento existentes no local, a precariedade habitacional, a demanda por unidades habitacionais e propõe alternativas de intervenção frente à problemática ao município.

Com base na leitura do PLHIS, o presente trabalho identificou as propostas e os meios de intervenções que o município de Itapetininga possui para atender a demanda de famílias que ocupam áreas irregulares, tendo como opção a urbanização (simples), urbanização (complexa), reassentamento (ou realocação) e remanejamento (ou relocação), dependendo da área em que estão localizadas.

Destacou-se o assentamento precário localizado no município de Itapetininga denominado "Pito Acesso", situado na Vila Palmeira, por se tratar de uma região crítica, desta forma apresentou-se o método de trabalho com o referido local e as famílias que ocupam a área de diretriz viária de utilidade pública.

Conforme pesquisa realizada é possível acreditar que com o PLHIS facilita análise a realidade e busca alternativas para crescimento do município aperfeiçoando a questão organizacional da cidade, promovendo melhoria na vida das famílias de baixa renda garantindo o Direito Constitucional visando moradias adequadas dando a elas infraestrutura adequada.

Foi possível observar que no município de Itapetininga há vários tipos de assentamentos e que há intervenções para cada um deles conforme escolha da Prefeitura Municipal de Itapetininga com orientação da equipe DEMACAMP que elaborou o Diagnóstico Social, para atender as áreas da melhor forma possível.

Portanto, conhecer para intervir é fundamental para que o trabalho seja bem elaborado junto ao município, cabendo ao gestor municipal se utilizar do Plano Local de Habitação de Interesse Social elaborado através do Diagnóstico Social, e empenhando se para que sejam executadas as intervenções trazendo o desenvolvimento econômico social e urbanístico ao município. 


\section{REFERÊNCIAS}

BRASIL. MINISTÉRIO DAS CIDADES, Secretaria Nacional de Habitação. Guia para o Mapeamento e Caracterização de Assentamentos Precários. Brasília: MCidades, 2010.

CARDOSO, A.L.; ARAUJO, R.L. de; GHILARDI, F.H. Necessidades habitacionais no Brasil. In: . Ações integradas de urbanização de assentamentos precários. Ministério das Cidades, 2010. Disponível em: > http://www.capacidades.gov.br/media/doc/biblioteca/SNH003.pdf $<$. Acesso em: 17 de abril de 2015.

DEMACAMP. Plano local de habitação de interesse social, 20111. Disponível em: $<$ http://www.franca. sp.gov.br/portal/index.php?Itemid=1227\&option=com_phocadownload\&view=category\&id=153 $>$. Acesso em: 25 Abr. 2015.

DENALDI, R. Planejamento Habitacional: notas sobre a precariedade e terra nos planos locais de habitação. São Paulo: Annablume, 2013.

. Plano de Ação Integrada em Assentamentos Precários. Disponível em: $<$ http://www. capacidades.gov.br/media/doc/biblioteca/SNH003.pdf >. Acesso em: 20 Abr. 2015.

FREITAS, L. H. El de. Plano Local de Habitação de Interesse Social. 2011. Relatório 2.2 Diagnóstico Habitacional Revisado, Interessado Prefeitura do Município de Itapetininga. 2010.

IPARDES, IPEA. Problemas Habitacionais dos Assentamentos Precários Urbanos na Região Metropolitana de Curitiba: projeto Caracterização e Tipologia Socioeconômica dos Assentamentos Precários Brasileiros Acordo de cooperação técnica. Curitiba: Ipardes: 2010.

PREFEITURA MUNICIPAL DE ITAPETININGA. Semanário Oficial de Itapetininga., Imprensa Oficial do Município, 28 de Dez. 2012., n. 343, p. 26.

PREFEITURA DE SÃO PAULO. Disponível em: < http://www.habisp.inf.br/habitacao >. Acesso em: 07 Maio 2015.

QUEIROZ FILHO, Alfredo Pereira de. As definições de assentamentos precários e favelas e suas implicações nos dados populacionais: abordagem da análise de conteúdo. Rev. Bras. Gest. Urbana, Curitiba, v. 7, n. 3, p. 340-353, Dec. 2015. Available from $<$ http://www.scielo.br/scielo.php?script=sci arttext\&pid=S2175-33692015000300340\&lng=en\&nrm=iso $>$. access on 17 Feb. 2016. Epub Sep 18, 2015. http://dx.doi.org/10.1590/2175-3369.007.003.AO03.

QUEIROZ FILHO, A. P. CONGRESO IBEROAMERICANO DE ESTUDIOS TERRITORIALES Y AMBIENTALES., 6. Disponivel em: < http://6cieta.org/arquivosanais/eixo6/Alfredo\%20Pereira $\% 20$ de\%20Queiroz\%20Filho.pdf >. Acesso em: 18 de Abr. 2015.

SANTA ROSA, J. ; DENALDI, R. Curso a distancia: planos locais de habitação de Interesse Social. Brasília: Ministério das Cidades, 2009. 
TURISMO CRIATIVO. As favelas cariocas como destino turístico. Disponível em: $<$ http://turismocriativo. blogspot.com.br/2010/02/as-favelas-cariocas-como-destino.html>. Acesso em: 07 Maio 2015.

URBANIZAÇÃO de Assentamentos Precários em São Paulo: o discurso da política e a prática da intervenção. In: SEMINÁRIO INTERNACIONAL PROCESSOS URBANOS INFORMALES. MEJORAMIENTO BARRIAL COMO RESPUESTA A UNA CIUDADE PARA TODOS., 2. Bogotá: Anais eletrônicos. Bogotá: Universidad Nacional de Colombia, 2012. Disponível em: $<$ http://www.fau. usp.br/pesquisa/napplac/trabalhos/mzuquim/mzuquim_art3.pdf >. Acesso em: 25 abr. 2015. 